\title{
Oral Cancer Awareness Among Dental Patients in Omdurman, Sudan: a cross- sectional Study
}

Tasneem Mohammed Babiker, Khansa Awad Alkareem Osman, Safa Abdelrawf Mohamed, Matab Abdalrhaman Mohamed and Hatim Mohammed Almahdi*

\begin{abstract}
Background: Oral cancer is a preventable disease. Its occurrence is mostly due to lifestyle. In Sudan, the use of smokeless tobacco (Toombak) has long been linked to oral cancer. Knowledge of the signs and symptoms of oral cancer may well aid in early diagnosis and treatment. This is bound to result in increasing survival rates, as well as reducing the oral cancer burden on the society. This study aimed to assess oral cancer awareness regarding knowledge of signs, symptoms, risk factors and sources of the information. Furthermore, it attempts to evaluate attitudes towards oral cancer screening and any previous experience of screening, amongst dental patients attending University of Science and Technology (UST) Dental Teaching Hospital. Omdurman, Sudan.
\end{abstract}

Methods: A hospital based cross-sectional study, interviewer-administered questionnaire was conducted amongst 500 adult patients attending the UST Dental Hospital during 2015.

Results: A total of $57.7 \%$ (286) of the individuals demonstrated good knowledge of signs and symptoms, whereas 49\% (139) expressed good knowledge of risk factors of oral cancer. For the majority of the individuals 66.1\% (290), the most common source of information about oral cancer was from the media, while 33.9\% individuals (149), obtained knowledge from direct contact of health workers. The overwhelming majority, 93.2\% (466) never screened for oral cancer despite their positive attitude towards it $66.4 \%$ (332). Knowledge of risk factors associated significantly with those reported positive attitude towards oral cancer screening and those reported direct contact with health workers as a source of information, $(p \leq 0.001)$. Moreover, females and those living in urban districts scores higher than their counterpart in knowledge of risk factor of oral cancer. In addition, those employed 58.6\% (280) and 62.8\% (164) with correct believes about oral cancer showed significant association with positive knowledge of signs and symptoms ( $p \leq 0.05)$.

Conclusions: Awareness levels, knowledge of risk factors and identifying early signs and symptoms of oral cancer necessitate the need for more structured preventive programs using media. Dentists and health workers should do more because they have a pivotal role in early diagnosis by performing oral cancer screening, raising levels of knowledge and in rectifying misconceptions about oral cancer. This would entail a reduction in high rates of morbidity and mortality associated with oral cancer.

Keywords: Oral cancer, Risk factors, Signs and symptoms, Knowledge, Attitude, Oral cancer screening, Smokeless tobacco, Toombak

* Correspondence: hatimalmahdi@gmail.com

Faculty of Dentistry, University of Science and Technology, Omdurman,

Sudan

(c) The Author(s). 2017 Open Access This article is distributed under the terms of the Creative Commons Attribution 4.0 International License (http://creativecommons.org/licenses/by/4.0/), which permits unrestricted use, distribution, and reproduction in any medium, provided you give appropriate credit to the original author(s) and the source, provide a link to the Creative Commons license, and indicate if changes were made. The Creative Commons Public Domain Dedication waiver (http://creativecommons.org/publicdomain/zero/1.0/) applies to the data made available in this article, unless otherwise stated. 


\section{Background}

Oral cancer (OC) which includes cancers of the lip, tongue and rest of the oral cavity, but not cancers of the major salivary glands [1], is responsible for sizeable morbidity and mortality rates worldwide especially in developing countries. While it is estimated that cancer incidence 14 million new cases, oral cancer alone claims about 300.000 deaths (2.1\%) annually with $1.8 \%$ mortality worldwide $[2,3]$.

Oral cancer in Sudan is ranked as the sixth amongst all cancers types (6.1 per 100.000) [4]. This is strongly attributed to the use of local type of smokeless tobacco (SLT) known as Toombak, which is popular in the Sudanese community. Toombak is made from finely ground leaves of Nicotiana rustica, and is mixed with natron or atron (sodium bicarbonate) and water. Natron or atron is probably added to Toombak for its alkaline effect and for fast absorption of nicotine to the central nervous system. Tobacco-specific nitrosamines (TSNA) levels in Sudanese Toombak were found to be unusually high compared to the reported levels in any other SLT. The etiologic association between Toombak use and oral cancer has been investigated by several studies [5-8].

Most of the oral cancer cases and deaths due to the individual susceptibility, linked to specific genetic attributes and exposure to carcinogens brought about by lifestyle behaviors [9].

Lifestyle behavior risk factors associated with oral cancer and other determinants of the disease, are interrelated with public knowledge of this disease [10]. Age, gender, tobacco use (smoked and smokeless), alcohol, infection (HPV, candida), lower socio-economic status, unhealthy diet with low fruit and vegetable intake, lack of physical activity are among the known risk factors for oral cancer [11, 12].

The oral cavity is easily accessible for self or clinical examination to detect lesions that are potentially malignant which can make early detection and diagnosis of the oral cancer achievable. Subsequently, this can significantly reduce the diagnostic delays of oral cancer which estimated to be $50 \%$ of cases [13-15]. Screening for oral cancer by visual and palpation assessment is still controversial as there is no evidence of the effectiveness of such assessment in reducing mortality from oral cancer. However, it is still recommended that dentists should "remain vigilant for signs of potentially malignant disorders (PMD) and oral cancer while performing routine oral examinations in practice" $[1,16,17]$.

Typical signs and symptoms of oral cancer includes, white and red patches on the lining of the oral mucosa, unhealed oral ulcers, swellings of the mouth, loosening of one or more teeth without obvious reason, jaw pain and stiffness, difficulty or pain in swallowing, speech difficulties, reduced mobility of the tongue, numbness of the tongue or teeth or lips, bleeding of unknown origin, neck swelling, fetor oris, altered dental occlusion, sore throat, painful tongue, hoarse voice and persistent neck pain [12].

Oral cancer is a preventable disease along with increased knowledge of oral cancer risk factors, signs and symptoms and this in turn is directly related to the prognosis of the cases identified. This is due to the fact that reinforcement of awareness on oral cancer can possibly lead to detection of early clinical presentation and hence early diagnosis. Moreover, oral cancer can be reduced by limiting the risk factors and early detection of signs and symptoms $[1,18]$.

This study was conducted in Omdurman, which is the largest city in Khartoum state, the capital of Sudan. It consists of three administrative localities; Omdurman, Umbadda and Karary. A total of more than 2 million inhabitants (2.215.33) account for almost $42 \%$ of population of the capital [19]. The University of Science and Technology (UST) Dental Teaching Hospital is serving around 15.000 patients a year.

Studying the awareness of early signs, symptoms and risk factors of oral cancer can really aid in preventing the disease, minimizing the problem consequences and help to establish preventive community program. This study aimed to investigate the awareness of oral cancer regarding knowledge of signs, symptoms and risk factors and source of information, in addition to previous oral cancer screening and attitude towards it among patients attended UST Dental Teaching Hospital during the year 2015. However, to ensure effectiveness of preventive programs; the understanding of the awareness the public of oral cancer risk factors, signs and symptoms is a first step in the process of behavioral change which can lead to avoid them.

\section{Methods}

This hospital-based cross-sectional study was carried out during the year 2015; using an interview questionnairebased to survey patients attending UST Dental Teaching Hospital at the Faculty of Dentistry, Omdurman.

\section{Sampling procedure}

A total of 500 participants were recruited using a census sampling procedure. Participants were adult dental patients ( $\geq 18$ years) who agreed to take part and signed the consent. Patients who attended the hospital on emergency basis and those with communication disabilities were excluded from the study. The interviews were conducted during their presence at the hospital.

\section{Data collection}

The data collection was supervised by trained personnel (authors). In order to make each participant feel as 
comfortable as possible, they were interviewed privately after a brief explanation of the objectives of the study and also responding to their questions and concerns. Interviewer-administered questionnaire was adapted from previously validated items that have been applied in similar studies [20-22]. The questionnaire was adapted to make it suitable for the local population of Omdurman city, especially in the part of risk factors associated with oral cancer. The questionnaire was comprised of close ended questions. It was divided into sections; demographic characteristics, knowledge of oral cancer signs, symptoms, risk factors, oral cancer screening experience and attitude towards the screening and believes about oral cancer (Additional file 1). A pilot study was performed on a sample of dental patients $(n=$ 30) attended the UST Dental Teaching Hospital, and the and the relevant and needed amendments, were performed for the final questionnaire.

\section{Questions and variables \\ Demographic characteristics}

Age group assessed by the question "what is your age" response options recoded into (0) "< 40 years", (1) " $\geq$ 40 years".

Education level assessed by the question "what is your education level" using response options (1) "primary level"; (2) "secondary level"; (3) "university"; (4) "postgraduate". The original categories recoded into (0) basic education (includes responses 1,2); (1) "university and post-university education" (includes responses 3,4 ).

Employment was assessed via the question "what is your occupation" using response options (1) "students"; (2) "labor"; (3) "employee"; (4) "unemployed"; (5) "professional"; (6) "retired". The original categories recoded into (0) unemployed (including original categories 4, 6); (1) employed (including original categories 1, 2, 3, 5).

Residence was assessed via the question "where is your residence" using response options (1) "suburban"; (2) "urban"; (3) "city". The original categories recoded into (0) suburban (including the original categories 1); (1) urban (including the original categories 2,3).

Sources of information was assessed via the question; "from where did you get this information" using response options (1) "general media (TV, radio)", (2) "internet (social media)", (3) "health workers", (4) "news- paper and magazine", (5) "other people". The original categories recoded into (0) from media (includes original response $1,2,4) ;(1)$ from direct contact (includes 3, 5, 6).

Heard of oral cancer was assessed via the question; "have you heard of oral cancer"; using response options (1) "yes"; (2) "no"; (3) "I don't know". The original categories recoded into (0) no (includes original response 2 , 3); (1) yes (includes original response 1).
Believes about oral cancer was assessed via four questions; "Does the risk factors of oral cancer increase with age"; "is oral cancer a preventable disease"; using response options (1) "yes"; (2) "no"; (3) "I don't know". The original responses recoded into (0) false beliefs (includes original response 2, 3); (1) correct beliefs (includes original response 1); "is oral cancer is contagious"; using response options (1) "yes"; (2) "no"; (3) "I don't know". The original categories recoded into (0) false beliefs (includes original response 1); (1) correct beliefs (includes original response 2,3); "is treatment of oral cancer possible"; using response options (1) "yes"; (2) "no"; (3) "I don't know". The original categories recoded into (0) false beliefs (includes original response 2, 3); (1) correct beliefs (includes original response 1). The sum variable "believes about oral cancer" (Cronbach's alpha $\alpha=.30)$ was constructed from the questions (0-4), with median split (Median 3, IQR 1), (0) false beliefs (includes original categories $0,1,2)$; (1) correct beliefs (includes original category 3,4$)$.

Knowledge of signs and symptoms was assessed via thirteen questions; "do you think loss of taste is a sign of oral cancer"; "do you think dry mouth is a sign of oral cancer"; "do you think bleeding from the gum is a sign of oral cancer"; "do you think burning sensation is a sign of oral cancer"; "do you think numbness of the tongue or other area of the mouth is a sign of oral cancer"; "do you think difficulty in chewing or swallowing is a sign of oral cancer"; "do you think an abnormal swelling is a sign of oral cancer"; "do you think soreness in the mouth that bleed easily and doesn't heal is a sign of oral cancer"; "do you think undue falling or loosing of teeth is a sign of oral cancer"; "do you think continues pain in the jaw is a sign of oral cancer"; "do you think white/red patch on the gum is a sign of oral cancer"; "do you think lump or thickening in the neck is a sign of oral cancer"; "do you think color change is a sign of oral cancer" using response options (1) "yes"; (2) "no"; (3) "i don't know". The original categories recoded into (0) poor knowledge (includes original response 2, 3); (1) good knowledge (includes original response 1 ). The sum variable "knowledge of signs and symptoms" (Cronbach's alpha $\alpha=.90$ ) was constructed from the 13 questions $(0-13)$ with median split (median7,IQR 6); (0) poor knowledge (includes original categories $0,1,2,3,4,5,6$, ); (1) good knowledge (includes 7, 8,9,10,11,12,13).

Knowledge of risk factors of oral cancer was assessed via eleven questions; "do you think smokeless tobacco (Toombak) is a risk factor"; "do you think (smoking (cigarette/shisha) is a risk factor"; "do you think alcohol is a risk factor"; "do you think family history of oral cancer is a risk factor"; "do you think exposure to sunlight is a risk factor"; "do you think old age is a risk factor"; "do you think poor oral hygiene is a risk factor"; "do you 
think chronic trauma is a risk factor"; "do you think sedentary life style is a risk factor"; "do you think hot and spicy food is a risk factor"; "do you think spiritual/ demonic attack is a risk factor". Using response options (1) "strongly agree", (2) "agree", (3) "undecided/neutral", (4) disagree, (5) "strongly disagree". The original categories recoded into (0) poor knowledge of risk factors (includes 3, 4, 5); (1) good knowledge of risk factors (includes original response 1,2 ). The sum variable "knowledge of risk factor" (Cronbach's alpha $\alpha=.65$ ), was constructed from 11 questions $(0-11)$ with median split (median 5, IQR 2); (0) poor knowledge includes original categories $0,1,2,3,4)$; (1) good knowledge (includes original categories $5,6,7,8,9,10,11$ ).

Attitude towards oral cancer screening was assessed via the questions; "do you think oral cancer screening should be mandatory"; using response options (1) "yes", (2) "no", (3) "i don't know". The original categories recoded into (0) negative attitude (includes original responses 1,2); (1) positive attitude (original responses 1).

Ever screened for oral cancer was assessed via the question; "have you ever gone to oral cancer examination (screening)"; using response options (1) "yes", (2) "no", (3) "i don't know". The original categories recoded into (0) not screened (includes original responses 2, 3); (1) ever screened (original responses 1).

\section{Data analysis}

Data were recorded and analysed using the Statistical Package for Social Science, version 20 (IBM. Chicago, Illinois, USA). Descriptive analyses were performed using frequencies and percentages. For the bivariate analysis chi-square tests were performed to evaluate the categorical variables; the level of significance was set at $p<0.05$ and $95 \%$ confidence intervals (95\% CI). Estimates were presented as Odds Ratio (OR) and 95\% confidence Interval (CI).

\section{Ethical consideration}

The Ethical Committee of the Faculty of Dentistry, University of Science and Technology, Omdurman, Sudan, approved the study protocol. Written informed consent obtained from all participants. Participation was voluntary, and participants were informed that they could withdraw at any time and that their responses would be anonymous and treated confidentially.

\section{Results}

\section{Sample profile}

As depicted in Table 1; a total of 68\% (340) of the participants were $<40$-years old, 64.4\% (322) were females. More than half of the participants 59\% (295) had university level of education. The majority $96.4 \%$ (482) was employed and $94.2 \%$ (471) were urban residents.
Table 1 Percentages and frequencies of demographic characteristics, source of information, oral cancer screening and attitude towards it and knowledge of signs, symptoms and risk factors of oral cancer

\begin{tabular}{|c|c|}
\hline Characteristics & Totals \% (n) \\
\hline \multicolumn{2}{|l|}{ Age } \\
\hline$<40$ & $68(340)$ \\
\hline$\geq 40$ & $32(160)$ \\
\hline \multicolumn{2}{|l|}{ Gender } \\
\hline Male & $35.6(178)$ \\
\hline Female & $64.4(322)$ \\
\hline \multicolumn{2}{|l|}{ Employment } \\
\hline Not employment & $3.6(18)$ \\
\hline Employment & $86.4(482)$ \\
\hline \multicolumn{2}{|l|}{ Residence } \\
\hline Suburban & $5.8(29)$ \\
\hline Urban & $84.2(471)$ \\
\hline \multicolumn{2}{|l|}{ Source of information } \\
\hline From media & $66.1(290)$ \\
\hline From direct contact & $33.9(149)$ \\
\hline \multicolumn{2}{|l|}{ Ever heard of oral cancer } \\
\hline No & $14.4(72)$ \\
\hline Yes & $85.6(428)$ \\
\hline \multicolumn{2}{|c|}{ Knowledge of signs and symptoms } \\
\hline Poor & $42.3(210)$ \\
\hline Good & $57.7(286)$ \\
\hline \multicolumn{2}{|l|}{ Knowledge of risk factors } \\
\hline Poor & $51(201)$ \\
\hline Good & $49(193)$ \\
\hline \multicolumn{2}{|c|}{ Ever screened for oral cancer } \\
\hline No & $93.2(466)$ \\
\hline Yes & $6.8(34)$ \\
\hline \multicolumn{2}{|c|}{ Attitude towards oral cancer screening } \\
\hline Negative attitude & $33.6(168)$ \\
\hline Positive attitude & $66.4(332)$ \\
\hline \multicolumn{2}{|l|}{ Believes about oral cancer } \\
\hline False belief & $47.5(237)$ \\
\hline Correct belief & $52.5(262)$ \\
\hline
\end{tabular}

Media including TV and internet is the main source of information about oral cancer to those $<40$ years $(69.8 \%$ (215), $p<0.05)$, and those with higher education $(69.4 \%$ (197), $p<0.05)$.

On analysis of individual signs and symptoms of oral cancer as depicted in Table 2, unhealed ulcer reported by $67.2 \%$ (336) of the participants, change in color $65 \%$ (325), white patches $63.6 \%$ (318) and soreness $62.4 \%$ 
Table 2 Percentages and frequencies of recognized signs, symptoms and risk factors of oral cancer

\begin{tabular}{|c|c|c|c|}
\hline Signs and symptoms & Totals \% (n) & Risk factors & Totals \% (n) \\
\hline Dry mouth & & Use of Toombak & \\
\hline No & $55.8(279)$ & No & $4.6(23)$ \\
\hline Yes & $44.2(221)$ & Yes & $95.4(477)$ \\
\hline Bleeding & & Smoking & \\
\hline No & $45.8(229)$ & No & $10.8(54)$ \\
\hline Yes & $54.2(271)$ & Yes & 89.2(446) \\
\hline Burning sensation & & Alcohol & \\
\hline No & $58.6(293)$ & No & 20.6(103) \\
\hline Yes & $41.4(207)$ & Yes & 79.4(397) \\
\hline Numbness & & Family history & \\
\hline No & $50.8(254)$ & No & $72.6(363)$ \\
\hline Yes & $49.2(246)$ & Yes & $27.4(137)$ \\
\hline Difficulty in chewing & & Exposure to sun & \\
\hline No & 48.9(244) & No & $80.6(403)$ \\
\hline Yes & $51.1(255)$ & Yes & 19.4(97) \\
\hline Difficulty in swallowing & & Aging & \\
\hline No & $51.2(256)$ & No & $69.4(347)$ \\
\hline Yes & $48.8(244)$ & Yes & $30.6(153)$ \\
\hline Soreness in mouth & & Bad oral hygiene & \\
\hline No & $37.5(187)$ & No & 29.4(147) \\
\hline Yes & $62.5(312)$ & Yes & $70.6(353)$ \\
\hline Teeth loosing & & Chronic irritation & \\
\hline No & $46.6(233)$ & No & 71.8(359) \\
\hline Yes & $53.4(267)$ & Yes & $28.2(141)$ \\
\hline Pain & & Sedentary life & \\
\hline No & $48.9(244)$ & No & $83.6(418)$ \\
\hline Yes & $51.1(255)$ & Yes & 16.6(82) \\
\hline White patches & & Spicy food & \\
\hline No & $36.3(181)$ & No & 69.8(349) \\
\hline Yes & 63.7(318) & Yes & $30.2(151)$ \\
\hline Swelling & & Spiritual & \\
\hline No & $45(225)$ & No & 78(390) \\
\hline Yes & $55(275)$ & Yes & $22(110)$ \\
\hline \multicolumn{4}{|l|}{ Change in color } \\
\hline No & $35(175)$ & & \\
\hline Yes & $65(325)$ & & \\
\hline \multicolumn{4}{|l|}{ Ulcer } \\
\hline No & $32.8(164)$ & & \\
\hline Yes & $67.2(336)$ & & \\
\hline
\end{tabular}

(312) were the most common identified signs and symptoms of oral cancer (Fig. 1).

Those of $<40$ years of age identified ulcer more than their counterparts 70\% (238), (OR 0.67, CI0.45-1.00, $p \leq$
0.05). Identification of change in color as sign and symptom of oral cancer recognized by those with positive attitude towards oral cancer screening scored higher than those with negative attitude 69\% (229), (OR 1.66, CI 1.13-2.44, $p \leq 0.05)$; and by females more than males 68.6\% (221), (OR 1.55, CI 1.06-2.27, $p \leq 0.05$ ), and also those $<40$ years scored higher than their counterparts 67.9\% (231), (OR 0.67, CI 0.45-0.99, $p \leq 0.05$ ).

White patches identified by those with positive attitude towards oral cancer screening 69.5\% (221), (OR 1.47, CI $1.00-2.15, p \leq 05)$, those ever heard of oral cancer $89 \%$ (283), (OR 2.00, CI 1.21-3.33, $p \leq 0.001$ ), and those $<$ 40 years $72 \%$ (229), (OR 0.61, CI $0.41-0.90, p \leq 05$ ).

The most common recognized risk factors of oral cancer were illustrated in Fig. 2. When comparing demographic characteristics, the higher education level found to be significantly associated with identifying Toombak as a risk factor for oral cancer as with more than two times likelihood (OR 2.32, CI 0.98-5.48, $p \leq$ $0.05)$. Also those with positive attitude towards screening reported 67.5\% (322), (OR 2.70, CI 1.15-6.29, $p \leq 0.05$ ).

Urban residents had better knowledge in identifying smoking as risk factor 90\% (446), with almost three times likelihood (OR 2.87, CI 1.16-7.07, $p \leq 0.001$ ). Those who heard of oral cancer had better knowledge in identifying smoking as risk factor with likelihood of more than two times than their counterparts (OR 2. 62, CI $1.36-5.06, p \leq 0.001$. Females reported alcohol and sedentary life style as risk factors more than males $83.2 \%$ (268), (OR 1.88, CI 1.21-2.92, $p \leq 0.001$ ) and $18.9 \%$ (61), (OR 1.74, CI 1.02-2.98, $p \leq 0.05$ ); respectively. Urban residents reported sedentary life style as risk factor more than suburban counterpart $17.2 \%$ (81), (OR 5.81, CI $0.78-43.35, p \leq 0.05)$. Family history reported as risk factor for oral cancer by those whom source of information by direct contact with health workers $34.9 \%$ (52), (OR 1.68, CI 1.09-2.59, $p \leq 0.05$ ).

Spiritual causes of oral cancer reported by those $\geq 40$ years as 30\% (48), (OR 1.92, CI 1.24-2.97, $p \leq 0.001$ ); and also those with basic education $33.7 \%$ (69) (OR 0.31, CI $0.20-0.49, p \leq 0.001$ ).

Demographic characteristics of those reported ever screened for oral cancer; a total of $7.4 \%$ (25) of those < 40 years, compared to $5.6 \%$ (9) $\geq 40$ years; $9 \%$ of males compared to $5.6 \%$ (18) females; higher educated confirmed screened more than their counterpart; moreover those residents in the urban 7\% (33) confirmed screened for oral cancer twice than those suburban residents $3.4 \%$ (1), (OR 2.11, CI 0.27-15.99).

Demographic characteristics of those reported positive attitude towards oral cancer screening; 68.9\% (222) of females were one and half times likelihood to report positive attitude (OR 1.57, CI 0.93-2.01), those in suburban 82.8\% (24) compared to $65.4 \%$ (308) in urban. Positive attitude towards 


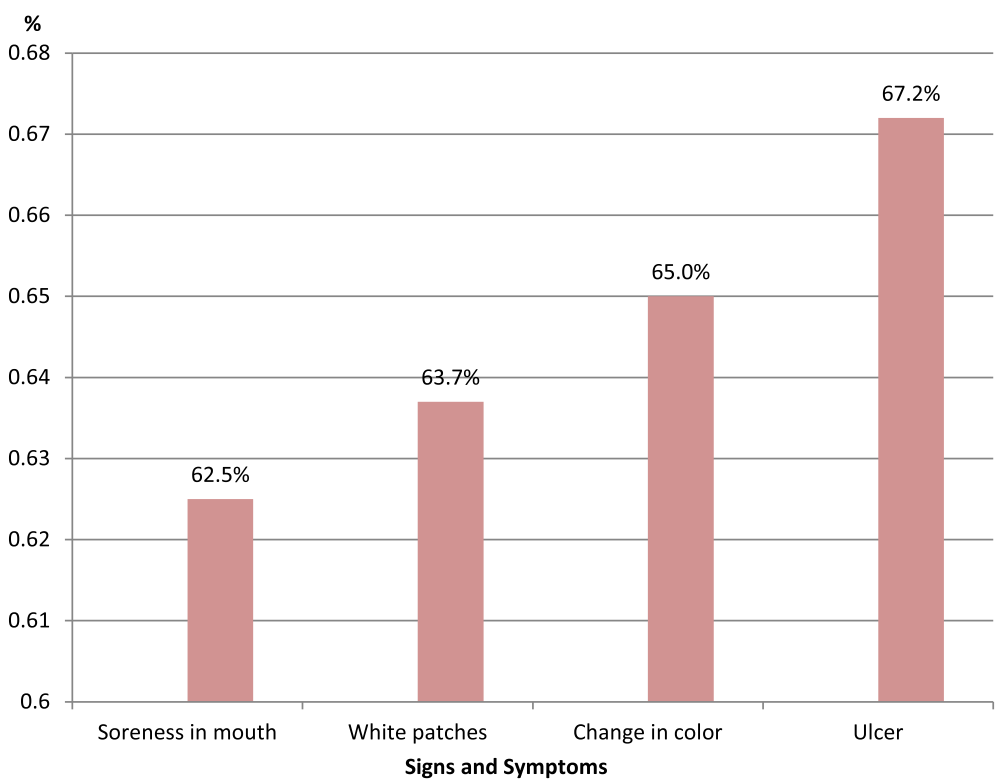

Fig. 1 The most common recognized signs and symptoms of oral cancer among the participants

oral cancer screening associated with correct beliefs about oral cancer $45.8 \%$ (152), $(p<0.05)$. Those confirmed good knowledge of signs and symptoms of oral cancer $62.5 \%$ (205) significantly report positive attitude as almost they were near two times likelihood than their counterpart $(p \leq$ 0.001).In addition, those with good knowledge of risk factors $53.9 \%(137)$ as one and half likelihood to report positive attitude towards screening of oral cancer Table 3.

\section{Discussion}

This study was conducted in UST Dental Teaching Hospital in Omdurman city, Sudan. It is worth noting

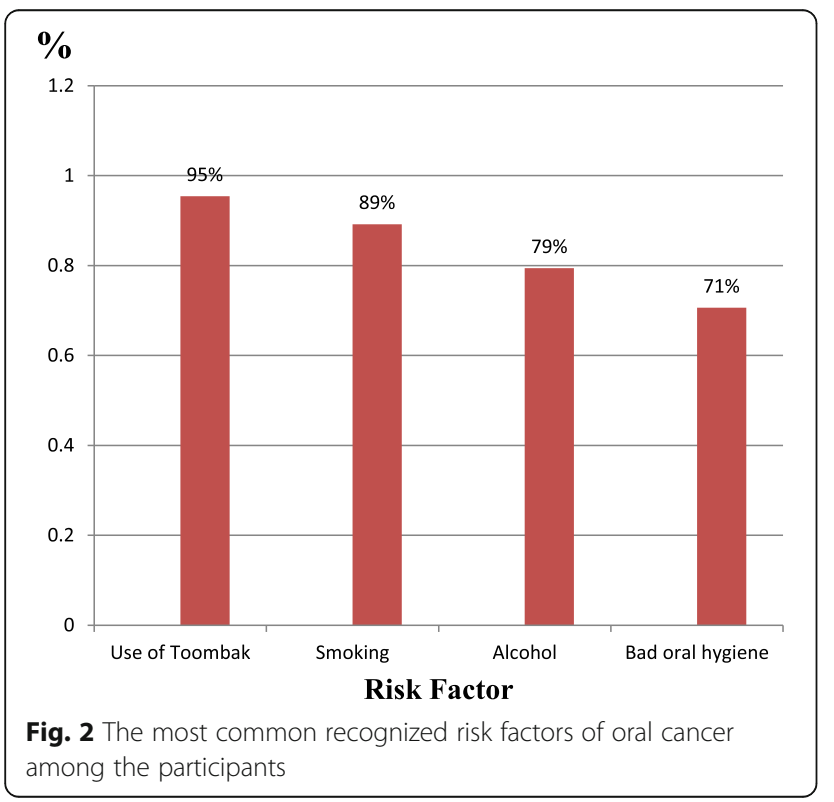

here that this study is the first of its kind in Sudan. The study provides valuable information about public awareness of risk factors, signs and symptoms of oral cancer.

Among the study participants knowledge of sign and symptoms affected significantly by employment (Table 3 ), but not affected by other demographic factors which contradicts other studies carried out among Iranians and Malaysians [23-25]. Those younger and females identified ulcers and change in color especially white patches as a sign and symptom for oral cancer better than their counterpart males; that may be contributed to females might be more aware of their well-being, and therefore might be more aware and concerned about any physical changes occurring to their body, in addition to the fact that females are more active in searching for health information than their counterpart male [26, 27].

Awareness of tobacco use (smoked and Toombak) as a risk factor for oral cancer scored high. That may be due to continuous anti-tobacco focus strategies such as ban on advertisements, increase the prices and taxes and restriction areas, which play a role in achieving behavioral change [28].

According to this study almost half of the participants reported negative believes about oral cancer in terms of whether it is contagious, treatable and/or preventable. This is probably due to misinformed public which is a similar situation to what has been revealed in Iran, Yemen and Jordan [23-25, 29].

A considerable portion of the sample in this study received their information via mass media. This in turn indicates the importance of mass media in educating the public and raising awareness about oral cancer signs, 
Table 3 Demographic characteristics, source of information, ever screened, and attitude towards oral cancer screening by good knowledge of signs, symptoms and risk factors of oral cancer

\begin{tabular}{|c|c|c|c|c|}
\hline \multirow[t]{2}{*}{ Characteristics } & \multicolumn{2}{|c|}{ Good knowledge risk factors of oral cancer } & \multicolumn{2}{|c|}{ Good knowledge of signs and symptoms of oral cance } \\
\hline & $\%(n)$ & $\mathrm{OR}(\mathrm{Cl})$ & $\%(n)$ & $\mathrm{OR}(\mathrm{Cl})$ \\
\hline \multicolumn{5}{|l|}{$\overline{\text { Age }}$} \\
\hline$<40$ & $47.0(124)$ & $1.27(0.83-1.94)$ & $58.9(199)$ & $0.85(0.58-1.25)$ \\
\hline$\geq 40$ & $53.1(69)$ & & $55.1(87)$ & \\
\hline \multicolumn{5}{|l|}{ Gender } \\
\hline Male & $44.8(65)$ & & $55.7(98)$ & $1.13(0.78-1.64)$ \\
\hline Female & $51.4(128)$ & $1.03(0.72-1.47)$ & $58.8(188)$ & \\
\hline \multicolumn{5}{|l|}{ Employment } \\
\hline Not employment & $35.3(6)$ & $1.80(0.65-4.97)$ & $33.3(6)$ & $2.82(1.04-7.66)$ \\
\hline Employment & 49.6(187) & & $58.6(280)^{*}$ & \\
\hline \multicolumn{5}{|l|}{ Residence } \\
\hline Suburban & $45.5(10)$ & $1.16(0.49-2.75)$ & $64.3(18)$ & $0.74(0.33-1.64)$ \\
\hline Urban & 49.2(183) & & $57.3(268)$ & \\
\hline \multicolumn{5}{|l|}{ Source of information } \\
\hline From media & $44.7(101)$ & $1.60(1.02-2.52)$ & $60.1(173)$ & $0.81(0.54-1.21)$ \\
\hline From direct contact & $56.5(65)^{*}$ & & $55.0 \%(82)$ & \\
\hline \multicolumn{5}{|l|}{ Ever heard of oral cancer } \\
\hline No & $48.4(30)$ & $1.02(0.59-1.77)$ & $54.3(38)$ & $1.17(0.70-1.95)$ \\
\hline Yes & 49.1(163) & & $58.2(248)$ & \\
\hline \multicolumn{5}{|c|}{ Ever screened for oral cancer } \\
\hline No & $48.9(180)$ & $1.04(0.47-2.31)$ & $57.4(265)$ & $1.20(0.58-2.45)$ \\
\hline Yes & $50(13)$ & & $61.8(21)$ & \\
\hline \multicolumn{5}{|l|}{$\begin{array}{l}\text { Attitude towards oral } \\
\text { cancer screening }\end{array}$} \\
\hline Negative attitude & $40(56)$ & $1.75(1.15-2.66)$ & $48.2(81)$ & $1.79(1.22-2.60)$ \\
\hline Positive attitude & $53.9(137)^{* *}$ & & $62.5(205)^{* *}$ & \\
\hline \multicolumn{5}{|c|}{ Believes about oral cancer } \\
\hline False believe & $47.9(90)$ & $1.07(0.72-1.60)$ & $51.2(122)$ & $1.55(1.08-2.22)$ \\
\hline Correct believe & 49.8(102) & & $62.8(164)^{*}$ & \\
\hline
\end{tabular}

${ }^{*} P \leq 0.05, * * P \leq 0.001$

symptoms and risk factors, which would entail an increase in early detection, diagnosis and thus survival rates [30]. The results confirm findings published in previous studies reporting that mass media is a common and effective source of information regarding oral cancer [29, 31, 32]. On the other hand, far less individuals obtained information from direct contact with health workers such as dentists. This fact highlights the need for dental professionals to advise and inform their patients about oral cancer. That is consistent with earlier studies carried out on Indian and Italian patients $[33,34]$.

This study reveals positive attitudes by participants towards screening for oral cancer but it also suggests ignorance of its existence, which is also demonstrated in other studies [35, 36]. Although visual examination proved to be effective in early detection and consequently reduces the mortality rate of oral cancer as a screening program [37], only few individuals of the participants were ever screened in the past for oral cancer. This is similar to has been reported by other studies from different parts of the world [38]. Dentists training and competency to perform oral cancer screening in their routine examinations may be questioned as some studies have emphasized [23, 39, 40]. Using the opportunity provided by a dental appointment to raise awareness may gradually encourage early detection of oral cancer, and as this study has indicated, screening of oral cancer is associated with good knowledge of signs, symptoms and risk factors (Table 1).

This study is not without its limitations, as the findings are based on interview reporting which might be subjected to recall bias and information bias (social 
desirability). Thus; participants may either have under or over-reported their responses to the questions.

Also, participation of this study was restricted to those who attended to UST Dental Teaching Hospital and this may set some limits on the generalizability of the results, given the nature and composition of the sample. Therefore, the results of this study, although portray an important picture of the current situation, should only be interpreted with caution.

\section{Conclusion}

Awareness levels, knowledge of risk factors and identifying early signs and symptoms of oral cancer necessitate the need for more structured preventive programs using media. Dentists and health workers should do more on this front since they have a pivotal role in early diagnosis by performing oral cancer screening, raising levels of knowledge and in rectifying misconceptions about oral cancer. This would entail a reduction in high rates of morbidity and mortality associated with oral cancer.

\section{Additional file}

Additional file 1: Questionnaire file: contains the questions and consent form in English and Arabic. (DOCX 167 kb)

\section{Abbreviations}

OC: Oral cancer; PMD: Potentially malignant disorders; SLT: Smokeless tobacco

\section{Acknowledgements}

The authors acknowledge the efforts and support provided by Dr. Safa Yagoub Babiker during the process of the study.

\section{Funding}

No funding was obtained for this study.

\section{Availability of data and materials}

The data that support the findings of this study are available from Ethical and Research Committee of Faculty of dentistry, University of Science and Technology, Omdurman, Sudan but restrictions apply to the availability of these data, which were used under license for the current study, and so are not publicly available. Data are however available from the authors upon request and with permission of Ethical and Research Committee of Faculty of dentistry, University of Science and Technology, Omdurman, Sudan.

\section{Authors' contributions}

The roles of the authors were: TM, KA, SA, MA, HMA contributed to the conception and design of the study, the acquisition of data, analysis and interpretation of data as part of their undergraduate thesis. HMA supervised and wrote the paper, have critically read and edited the paper. All authors have read and approved the final manuscript.

\section{Authors' information}

Dr. Hatim Mohammed Almahdi, BDS, MFD RCSI, MSC Head, Department of Oral and Maxillofacial Surgery, Faculty of Dentistry, University of Science and Technology, Omdurman, Sudan.

\section{Competing interests}

The authors declare that they have no competing interests.

\section{Ethics approval and consent to participate}

The Ethical Committee of the Faculty of Dentistry, University of Science and Technology, Omdurman, Sudan, approved the study protocol. Written informed consent obtained from all participants.

Received: 11 September 2016 Accepted: 21 February 2017

Published online: 23 March 2017

\section{References}

1. Early detection and prevention of oral cancer: a management strategy for dental practice. In: Edited by Paul Speight SW, Graham Ogden: British Dental Association; 2010

2. Stewart B. WC: World cancer report 2014. Lyon: International Agency for Research on Cancer, World Health Organization; 2014.

3. Ferlay J, Soerjomataram I, Dikshit R, Eser S, Mathers C, Rebelo M, Parkin DM, Forman D, Bray F. Cancer incidence and mortality worldwide: sources, methods and major patterns in GLOBOCAN 2012. I J Cancer. 2015;136(5):E359-86.

4. Saeed IE, Weng HY, Mohamed KH, Mohammed SI. Cancer incidence in Khartoum, Sudan: first results from the cancer registry, 2009-2010. Cancer Med. 2014;3(4):1075-84.

5. Idris A, Nair J, Ohshima H, Friesen M, Brouet I, Faustman E, Bartsch H. Unusually high levels of carcinogenic tobacco-specific nitrosamines in Sudan snuff (toombak). Carcinogenesis. 1991:12(6):1115-8.

6. Idris A, Prokopczyk B, Hoffmann D. Toombak: a major risk factor for cancer of the oral cavity in Sudan. Prev Med. 1994:23(6):832-9.

7. Osman TA, Satti AA, Bøe OE, Yang Y-H, Ibrahim SO, Suleiman AM. Pattern of malignant tumors registered at a referral oral and maxillofacial hospital in Sudan during 2006 and 2007. J Cancer Res Thera. 2010;6(4):473-7.

8. Ahmed HG. Aetiology of oral cancer in the Sudan. J Oral Maxillofac Res. 2013;4(2), e3.

9. Petti S. Lifestyle risk factors for oral cancer. Oral Oncol. 2009;45(4-5):340-50.

10. Luryi AL, Yarbrough WG, Niccolai LM, Roser S, Reed SG, Nathan C-AO, Moore MG, Day T, Judson BL. Public awareness of head and neck cancers: a cross-sectional survey. JAMA Otolaryngol Head Neck Surg. 2014;140(7):639-46.

11. Cancer IAfRo: Consumption of alcoholic beverages and Ethyl Carbamate (Urethane). Lyon: IARC Monographs on the Evaluation of Carcinogenic Risks to Humans; 2007. p. 96.

12. Wolff K-D, Follmann M, Nast A. The diagnosis and treatment of oral cavity cancer. Dtsch Arztebl Int. 2012;109(48):829-35.

13. Patton LL, Elter JR, Southerland JH, Strauss RP. Knowledge of oral cancer risk factors and diagnostic concepts among North Carolina dentists. Implications for diagnosis and referra. J Am Dent Assoc. 2005;136(5):602-10. quiz 682

14. Jafari A, Najafi S, Moradi F, Kharazifard M, Khami M. Delay in the diagnosis and treatment of oral cancer. J Dent (Shiraz). 2013:14(3):146-50.

15. Patton LL. The effectiveness of community-based visual screening and utility of adjunctive diagnostic aids in the early detection of oral cancer. Oral Oncol. 2003;39(7):708-23.

16. Walsh $T L J$, Brocklehurst $P$, Glenny AM, Lingen $M$, Kerr AR, et al. Clinical assessment to screen for the detection of oral cavity cancer and potentially malignant disorders in apparently healthy adults. Cochrane Database Syst Rev. 2013:(11):CD010173.

17. Brocklehurst P, Kujan O, O'Malley LA, Ogden G, Shepherd S, Glenny AM. Screening programmes for the early detection and prevention of oral cancer. Cochrane Database of Systematic Rev. 2013;(11):CD004150.

18. Mangalath U, Aslam SA, Khadar AHKA, Francis PG, Mikacha MSK, Kalathingal $J$ H. Recent trends in prevention of oral cancer. J Int Soc Prev Community Dent. 2014:4 Suppl 3:S131-8.

19. Central Bureau of Statitistcs. http://www.cbs.gov.sd/en/. Accessed 30 Dec 2016

20. Al-Maweri SA, Abbas A, Tarakji B, Al-Jamaei AS, Alaizari NA, Al-Shamiri HM Knowledge and opinions regarding oral cancer among Yemeni dental students. Asian Pac J Cancer Prev. 2015;16:1765-70.

21. Dubai SARA, Ganasegeran K, Alabsi AM, Alshagga MA, Ali RS. Awareness and knowledge of oral cancer among university students in Malaysia. Asian Pac J Cancer Prev. 2012;13(1):165-8

22. Agrawal M, Pandey S, Jain S, Maitin S. Oral cancer awareness of the general public in Gorakhpur City. India Asian Pac J Cancer Prev. 2012;13(10):5195-9.

23. Tadbir AA, Ebrahimi H, Pourshahidi S, Zeraatkar M. Evaluation of levels of knowledge about etiology and symptoms of oral cancer in southern Iran. Asian Pac J Cancer Prev. 2013;14(4):2217-20. 
24. Ghani WMN, Doss JG, Jamaluddin M, Kamaruzaman D, Zain RB. Oral cancer awareness and its determinants among a selected Malaysian population. Asian Pac J Cancer Prev. 2013;14:1957-63.

25. Hassona Y, Scully C, Abu Ghosh M, Khoury Z, Jarrar S, Sawair F. Mouth cancer awareness and beliefs among dental patients. Int Dent J. 2014;65(1):15-21.

26. Rice RE. Influences, usage, and outcomes of Internet health information searching: multivariate results from the Pew surveys. Int J Med Inform. 2006; 75(1):8-28.

27. Ek S. Gender differences in health information behaviour: a Finnish population-based survey. Health Promot Int. 2013;30(3):736-45.

28. Bader $P$, Boisclair D, Ferrence R. Effects of tobacco taxation and pricing on smoking behavior in high risk populations: a knowledge synthesis. Int J Environ Res Public Health. 2011:8(11):4118-39.

29. Al-Maweri SA, Addas A, Tarakji B, Abbas A, Al-Shamiri HM, Alaizari NA Shugaa-Addin B. Public awareness and knowledge of oral cancer in Yemen. Asian Pac J Cancer Prev. 2014;15:10861-5.

30. Macleod U, Mitchell E, Burgess C, Macdonald S, Ramirez A. Risk factors for delayed presentation and referral of symptomatic cancer: evidence for common cancers. Br J Cancer. 2009;101:S92-101.

31. Eadie D, MacKintosh AM, MacAskill S, Brown A. Development and evaluation of an early detection intervention for mouth cancer using a mass media approach. Br J Cancer. 2009;101 suppl 2:S73-9.

32. Saleh A, Yang Y-H, Ghani WMNWA, Abdullah N, Doss JG, Navonil R, Rahman ZAA, Ismail SM, Talib NA, Zain RB. Promoting oral cancer awareness and early detection using a mass media approach. Asian Pac J Cancer Prev. 2012;13(4):1217-24.

33. Reddy BS, Doshi D, Reddy MP, Kulkarni S, Gaffar A, Reddy VR. Oral cancer awareness and knowledge among dental patients in South India. J Craniomaxillofac Surg. 2012;40(6):521-4.

34. Villa A, Kreimer AR, Pasi M, Polimeni A, Cicciù D, Strohmenger L, Gherlone $E$, Abati S. Oral cancer knowledge: a survey administered to patients in dental departments at large Italian hospitals. J Cancer Educ. 2011;26(3):505-9.

35. Awojobi O, Scott SE, Newton T. Patients' perceptions of oral cancer screening in dental practice: a cross-sectional study. BMC Oral Health. 2012;12:55.

36. Reiter $\mathrm{P}$, Wee $\mathrm{A}$, Lehman A, Paskett E. Oral cancer screening and dental care use among women from Ohio Appalachia. Rural Remote Health. 2012;12:2184

37. Speight PM, Downer MC, Zakrzewska J. Screening for oral cancer and precancer. Are port of the UK working group on screening for oral cancer and precancer. Community Dent Health. 1993;10(supplement 1):1-89.

38. Awojobi O, Scott SE, Newton T. Patients' perceptions of oral cancer screening in dental practice: a cross-sectional study. BMC oral health. 2012;12:55.

39. Allen K, Farah C. Screening and referral of oral mucosal pathology: a checkup of Australian dentists. Aust Dent J. 2015;60(1):52-8.

40. Anandani C, Metgud R, Ramesh G, Singh K. Awareness of general dental practitioners about oral screening and biopsy procedures in Udaipur. India Oral Health Prev Dent. 2015:13(6):523-30.

\section{Submit your next manuscript to BioMed Central and we will help you at every step:}

- We accept pre-submission inquiries

- Our selector tool helps you to find the most relevant journal

- We provide round the clock customer support

- Convenient online submission

- Thorough peer review

- Inclusion in PubMed and all major indexing services

- Maximum visibility for your research

Submit your manuscript at www.biomedcentral.com/submit 